\title{
Development of an on-line problem-oriented system for the evaluation of mental health treatment services
}

\author{
RONALD A. GIANNETTI, JAMES H. JOHNSON, and THOMAS A. WILLIAMS \\ Veterans Administration Hospital, Salt Lake City, Utah 84148 \\ and \\ University of Utah College of Medicine, Salt Lake City, Utah 84132 \\ and \\ CHARLES F. McCUSKER \\ Veterans Administration Hospital, Salt Lake City, Utah 84148
}

\begin{abstract}
Current on-line assessment applications are limited to mimicking instruments designed for paper and pencil. The development of an instrument designed specifically for on-line technology is described. The instrument provides research data on treatment effectiveness, clinical information for treatment planning, and management information for resource allocation.
\end{abstract}

On-line computer technology makes available a fundamentally different and more powerful medium than the standard paper-and-pencil methods for assessment and evaluation of psychiatric patients. We have previously argued that assessment instruments should be designed to take advantage of the on-line medium rather than limiting computer applications to the mimicking of assessment techniques developed for the paper-and-pencil medium (Giannetti, Klingler, Johnson, \& Williams, 1976). The purpose of this paper is to describe our progress in the development of such an application: a structured, problem-oriented instrument for the evaluation of the progress and outcome of patients receiving mental health treatment services.

By designing a problem-oriented instrument specifically for use with on-line computer technology, it is possible to design an instrument with great flexibility. First, the instrument provides researchers with a readily accessible data base for the study of treatment effectiveness. Second, it provides treatment staff with an immediate, complete summary of a patient's clinical condition prior to the initiation of treatment planning. Third, it provides the therapists with feedback on the impact of therapeutic efforts during treatment, at termination of treatment, and at follow-up. Finally, it provides managers of the treatment system with information on the success or failure of the system in accomplishing its goals. The problem-oriented instrument is one component of a battery of psychological and physical assessment instruments currently used at

Reprint requests should be addressed to Ronald A. Giannetti, Systems and Evaluation Unit, VA Hospital, 500 Foothill Drive, Salt Lake City, Utah 84148. the Psychiatric Assessment Unit (PAU) for the intake evaluation of applicants for mental health services at the Salt Lake Veterans Administration Hospital. This system has been described in detail elsewhere (Johnson, Giannetti, \& Williams, 1975; Johnson \& Williams, 1975; Williams, Johnson, \& Bliss, 1975)

\section{DEVELOPMENT OF THE PROBLEM LIST SYSTEM}

The rationale for a problem-oriented evaluation system stems from Weed's (1969) restructuring of medical records from the traditional source-oriented format to a format which records all diagnostic, treatment, and progress information in relation to a master list of problems defined in the patient's record. However, implementation of this format has been made difficult in mental health treatment settings by virtue of the fact that there are no uniformly acceptable definitions and categorizations of mental health problems. For example, listing a diagnosis as a problem conveys insufficient information for a behaviorally oriented therapist to begin planning a behavior modification treatment strategy. Alternatively, listing problems in terms of molecular behaviors produces such specificity so as to prohibit a psychiatrist from planning psychopharmacological treatment. Despite this lack of uniformly acceptable problem definitions, there have been several attempts by behavioral scientists to produce mental health problem lists. Examination of these lists reveals a remarkable degree of overlap in content and rather minimal differences in the level of abstraction at which the problems are stated. Thus, it appears that the construction of a standard problem list is a feasible enterprise. 


\section{CONSTRUCTION OF THE PROBLEM LIST}

A list of 248 problems was compiled after reviewing several existing problem lists, including a behavioral list developed by Cautela and Upper (Note 1), a treatment goal-oriented list (Gianturco \& Ramm, 1974), a list used in program evaluation at Fort Logan Mental Health Center (Wilson, Ellis, Booth, \& Mumpower, Note 2), and a content analysis (Garwick \& Lampman, 1972) of problems generated from goal attainment scaling (Kiresuk \& Sherman, 1968). Furthermore, several problems not evident in previous lists were added by the authors. The final list includes problems in the broad categories of orientation; memory; organic impairment; substance abuse; affect/mood disturbance; disturbance of perception, ideation, and speech; intellectual/learning deficits; motor disturbances; somatic disturbances; sleep difficulties; self-injurious behavior; antisocial behavior; sexual problems; trait disturbances; family and marital difficulties; vocation and financial difficulties; problems of daily living; and treatment problems. The problems were numbered consecutively and assembled into a problem dictionary.

One of the purposes of any structured problemoriented system is to obtain a measure of the improvement in a patient's condition. Given a structured list of problems, we anticipated that a measure of improvement could be based on clinician ratings, for each individual patient, of the "severity" level of each of the various problems. However, the problems themselves possess an inherent hierarchy of severity. For example, it is intuitively obvious that auditory hallucinations of moderate severity are more disabling to a patient's functioning than is an equally severe fear of insects.

Given this consideration, it was decided to assign a weight to each problem that would reflect the relative degree of impairment in personal and social functioning implied by that problem. This was accomplished by having five clinicians complete a nine-category Q-sort (Block, 1961) of the 248 rationally derived problems. The Q-sort was based on the clinicians' judgments of the relative degree of functional disability implied by each problem. A "disability weight" was assigned to each problem by averaging its Q-sort ranks across the five sorts. The mean intercorrelation among the judges' sorts was .55 , making the reliability of the compositive weights .84 . The weights ranged from a high of 9.0 for the problem of "homicide" to a low of 1.7 for the problem of "fear of insects."

After determining the disability weights, a scale for rating the severity of individual problems was constructed. This is simply a six-point scale of increasing severity with the following anchors: "minimal," "mild," "moderate," "marked," "severe," and "extreme."

A measure of the degree of functional impairment on an individual problem, or "disability score," was then operationally defined as the product of the "disability weight" assigned to that problem and the individual clinician/patient rating of the "severity" of that problem. The total "disability score" for an individual patient is the sum of the disability scores across the number of problems. Thus, the resulting score reflects the number of problems defined, their disabling effect, and their severity.

When a new set of ratings is obtained on the patient's problems after a period of treatment, a measure of change can be calculated. The "disability difference" is defined as the euclidian distance between the two sets of disability scores. The number of problems determines the dimensionality of the space in which the distance is calculated. That is, each problem is considered to be an independent dimension in determining disability.

\section{FUNCTIONAL USE OF THE PROBLEM LIST}

\section{Intake}

The problem list is the final assessment device which is used at the PAU in the intake evaluation of mental health patients. By virtue of the short response times of the on-line assessment system, the evaluator has computerized results from the mental status examination, personality testing, intellectual testing, and the social history previous to the development of a patient's problem list. After reviewing these results with the patient, the evaluator constructs the problem list.

The computerized problem list program is initiated by selecting the problems which are appropriate for the patient from a dictionary of structured problems (this is in the form of a noncomputerized code book) and then entering the relevant problem numbers with their associated severity ratings into the computer via a cathode-ray-tube (CRT) terminal. After entering all appropriate problems, the evaluator enters an overall severity rating from the Health-Sickness Scale (Luborsky, 1962). When this procedure is completed, an initial problem list report is printed by the computer. An example of the computerized problem list report is shown in Figure 1.

PROBLEH/INTERVENTIOH ORIENTED MEDICAL RECORD PSYCHO-SOCIAL DISABILITY EVALUATION - INTAKE

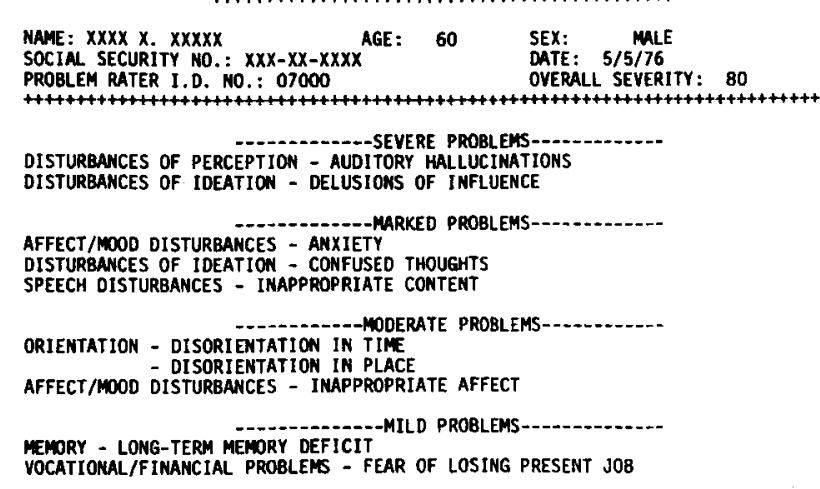

Figure 1. An intake problem list. 
This report format facilitates the initiation of treatment. It provides a brief summary of the results of an extensive assessment battery. It lists the problems in descending order of disability so that a priority for treatment is established in an objective manner. Finally, since it is complementary with the structure of the medical record, it facilitates the recording of treatment data.

The therapist chooses from among three alternatives in dealing with the problems. First, he may group problems for which he intends to use the same treatment, for example, an antipsychotic medication. Second, he may defer problems which are not treated by him, for example, a marital problem may be deferred while the patient is undergoing acute treatment procedures. Finally, he may add problems uncovered during treatment which were not identified at intake. These procedures require the therapist to make his treatment decisions overt. The results of these decisions are recorded in the computer when a reevaluation of the patient's status on the problems is made.

\section{Reevaluation}

The problem list is also used for reevaluating the patient periodically during treatment, at termination of treatment, at follow-up, and at readmission to treatment. All reevaluations are completed by PAU staff members. The rater reviews the progress notes in the patient's chart. These notes are recorded by grouped problems. He interviews the patient to determine the current status on each of the individual problems and enters his severity ratings into the CRT. He also enters the numbers of problems which have been grouped, deferred, and added. An example of the report produced by this procedure is shown in Figure 2.

The report begins with a summary of all the evaluations completed on the patient. In this case we have evaluations at intake and at termination of inpatient treatment. The summary identifies the date, location, responsible therapist, type of evaluation, and primary diagnosis of the patient. The disability score and disability difference score are currently reported as averages over the number of problems since standardization of

NAME: $\mathrm{XXX} X . \mathrm{XXXX}$

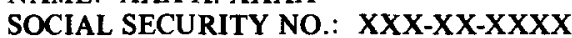

SEX: MALE

AGE: 60

DATE: $5 / 28 / 76$

PROBLEM RATER ID NO.: 10001

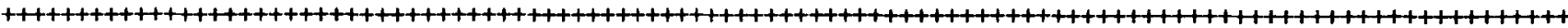
SUMMARY OF EVALUATIONS

\begin{tabular}{|c|c|c|c|c|c|c|c|c|}
\hline \multicolumn{9}{|c|}{ SUMMARY OF EVALUATIONS } \\
\hline OCCASION & DATE & LOCATION & $\begin{array}{l}\text { THERAPIST/ } \\
\text { ADVOCATE }\end{array}$ & $\begin{array}{c}\text { PROBLEM } \\
\text { RATER }\end{array}$ & $\begin{array}{c}\text { PRIMARY } \\
\text { DIAG. }\end{array}$ & $\begin{array}{l}\text { AVERAGE } \\
\text { DISABILITY }\end{array}$ & $\begin{array}{l}\text { AVE. } \\
\text { DIFF }\end{array}$ & $\begin{array}{c}\text { TOTAL } \\
\text { DIFF }\end{array}$ \\
\hline $\begin{array}{l}\text { INTAKE } \\
\text { INP TERM }\end{array}$ & $\begin{array}{l}5 / 5 / 76 \\
5 / 28 / 76\end{array}$ & $\begin{array}{l}\text { VAH } \\
\text { VAH }\end{array}$ & 01044 & $\begin{array}{l}07000 \\
10001\end{array}$ & $\begin{array}{l}295.90 \\
295.90\end{array}$ & 15.37 & 22.07 & 22.07 \\
\hline
\end{tabular}

\section{MARKED PROBLEMS}

DISTURBANCES OF IDEATION - DELUSIONS OF INFLUENCE

MODERATE PROBLEMS

DISTURBANCES OF PERCEPTION - AUDITORY HALLUCINATIONS

MILD PROBLEMS

AFFECT/MOOD DISTURBANCES - ANXIETY

DISTURBANCES OF IDEATION - CONFUSED THOUGHTS

SPEECH DISTURBANCES - INAPPROPRIATE CONTENT

AFFECT/MOOD DISTURBANCES - INAPPROPRIATE AFFECT

\section{DEFERRED PROBLEMS}

VOCATIONAL/FINANCIAL PROBLEMS - FEAR OF LOSING PRESENT JOB

MEMORY - LONG-TERM MEMORY DEFICIT

ORIENTATION - DISORIENTATION IN TIME

ORIENTATION - DISORIENTATION IN PLACE

PROBLEMS GROUPED FOR TREATMENT

$53,36,26,41,60,31$

OVERALL SEVERITY 55

OVERALL SEVERITY DIFFERENCE FROM INTAKE 25.00 
RELATIVE COMPARISON OF (SLM OF SEVERITIES TIMES WEIGHT) OF PROBLEMS ASSIGNED AT INTAKE

SAMPLE $1 / 30 / 76$ to $2 / 29 / 76$

MEAN $=84.67$ SD $=178.37 \mathrm{~N}=118$

PROB. TIMES

NO. ASSIGNED
SUM OF SEVERITIES

RELATIVE MAGNITUDE OF

SUM OF SEVERITIES TIMES WEIGHT

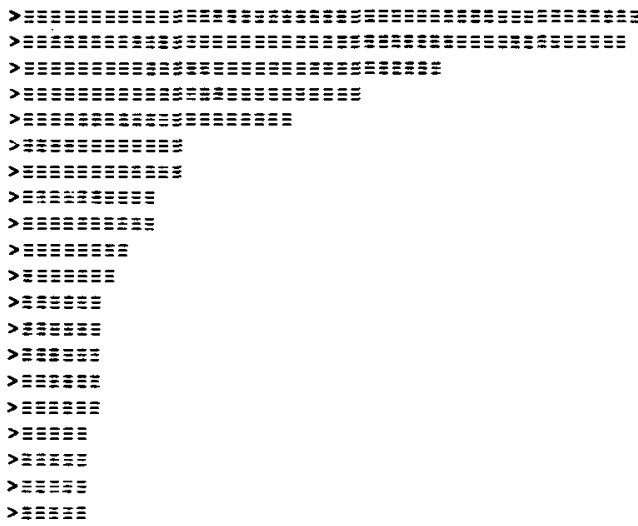

TIMES WEIGHT

$\begin{array}{ll}1211.00 & \text { DEPRESSION } \\ 1101.60 & \text { ALCOHOL ABUSE } \\ 756.40 & \text { ANXIETY } \\ 620.00 & \text { NO JOB } \\ 488.80 & \text { GUILT/SHAME } \\ 310.00 & \text { CONFUSED THOUGHTS } \\ 292.80 & \text { SOCIAL ISOLATION } \\ 257.60 & \text { DIFFICULTY CONCENTRATING } \\ 251.60 & \text { AUDITORY HALLUCINATIONS } \\ 204.60 & \text { LONG-TERM MEMORY DEFICIT } \\ 175.00 & \text { ANGER/HOSTILITY } \\ 166.40 & \text { SUICIDAL IDEATION } \\ 166.40 & \text { AGITATION/HYPERACTIVITY } \\ 156.40 & \text { INADEQUATE SLEEPING } \\ 149.60 & \text { SUSPICIOUSNESS } \\ 148.20 & \text { PERSECUTORY DELUSIONS } \\ 136.40 & \text { NO RESIDENCE } \\ 134.40 & \text { DOES NOT TAKE PRESCRIBED MEOICATIONS } \\ 125.80 & \text { SUICIDE GESTURE/ATTEMPT } \\ 121.60 & \text { READMISSION TO TREATMENT }\end{array}$

Figure 3. The intake problem summary.

these scores is still in progress. The first difference score is calculated between the previous and current evaluation. The total difference score is calculated between the initial and current evaluation. The remainder of the report summarizes the patient's current status on the problems and the treatment decisions in terms of grouped, deferred, and added problems. This report is returned to the therapist as feedback on his performace with the patient.

\section{USE OF THE PROBLEM LIST FOR MANAGEMENT INFORMATION}

The data collected by the above two procedures are sufficient to provide valuable information on the functioning of the treatment system for both the staff and administrators. Two simple batch programs are used to produce the required information.

The first management information report serves two functions. It summarizes the behavior of the intake raters. By reporting the average number of problems assigned per patient and the average severity ratings for each rater, it allows the PAU staff to compare their ratings and immediately identifies anyone whose ratings become deviant. A report of this type is imperative in an ongoing clinical setting since the alternative of performing routine interrater reliability studies to examine rater behavior is impractical.

The second function of this report (part of which is reproduced in Figure 3 ) is to permit management to identify the most frequent and disabling problems which confront the treatment system. The report is a list of the problems identified at intake, rank ordered by the sum of the disabilities accrued to that problem. The information is necessary for appropriate resource alloca- tion decisions. In fact, this reporting scheme has already resulted in the diversion of resources at this institution into vocational rehabilitation services, due to the identification of large numbers of unemployed patients.

DISABILITY REPORT

Report from $1 / 30 / 76$ to $2 / 29 / 76$

ACUTE INPATIENT TREATMENT UNIT

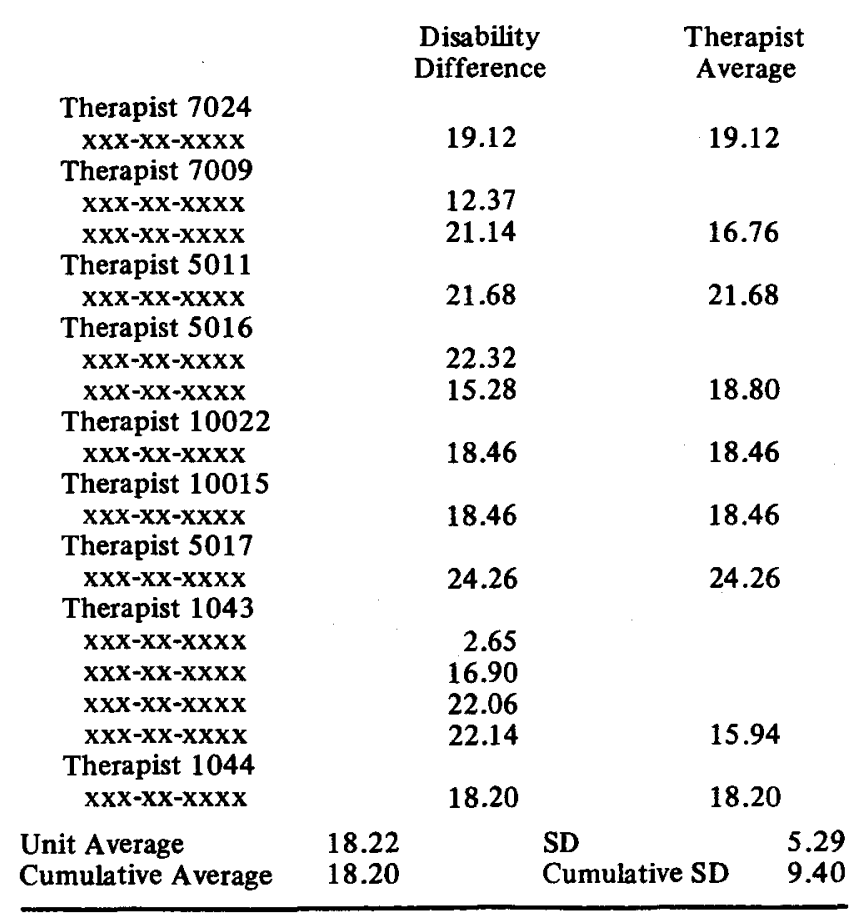

Figure 4. Report to a unit on patient treatment. 


\begin{tabular}{|c|c|c|c|c|}
\hline \multicolumn{5}{|c|}{ PIFM RFPORT } \\
\hline Problem & $\begin{array}{c}\text { Average Disability } \\
\text { Difference }\end{array}$ & $\begin{array}{l}\text { Severity } \\
\text { Difference }\end{array}$ & \multicolumn{2}{|c|}{ Number of Times } \\
\hline 4-Short-term memory deficit & 3.50 & .50 & 1 & 1 \\
\hline 8-Dissociation & 9.90 & 1.50 & 2 & 0 \\
\hline 11-Epilepsy (Grand Mal) & 16.21 & 2.53 & 2 & 0 \\
\hline 12-Epilepsy (Petit Mal) & 0 & 0 & 0 & 1 \\
\hline 24-Vapor inhalation & 0 & 0 & 0 & 1 \\
\hline 25-Anger/hostility & 6.92 & 1.38 & 3 & 1 \\
\hline 26-Anxiety & 24.31 & 3.92 & 10 & 0 \\
\hline 27-Depression & 29.88 & 4.27 & 11 & 0 \\
\hline 29-Flat affect & 10.40 & 2.00 & 1 & 0 \\
\hline 30-Guilt/shame & 13.17 & 2.53 & 4 & 2 \\
\hline 35-Illusions & 0 & 0 & 1 & 0 \\
\hline 36-Auditory hallucinations & 19.73 & 2.67 & 3 & 0 \\
\hline 37-Visual hallucinations & 24.60 & 3.00 & 2 & 0 \\
\hline 42-Difficulty concentrating & 24.27 & 4.33 & 3 & 0 \\
\hline 44-Excessive rumination & 24.00 & 5.00 & 0 & 1 \\
\hline 46-Obsessions & 23.20 & 4.00 & 1 & 0 \\
\hline 47-Suicidal ideation & 21.56 & 3.37 & 7 & 1 \\
\hline 48-Ideas of reference & 19.23 & 2.91 & 2 & $\mathbf{0}$ \\
\hline 49-Grandiose delusions & 28.66 & 3.87 & 1 & $\mathbf{0}$ \\
\hline 50-Persecutory delusions & -1.90 & -.24 & 2 & $\mathbf{0}$ \\
\hline 52-Somatic delusions & 24.01 & 3.87 & 1 & $\mathbf{0}$ \\
\hline 57-Disorganized speech & 19.80 & 3.00 & 1 & 0 \\
\hline 78-Agitation/hyperactivity & 0 & 0 & 1 & 0 \\
\hline 92-Underweight & -4.47 & -2.24 & 1 & 0 \\
\hline 108 -Fear of killing someone & 27.00 & 5.00 & 1 & 0 \\
\hline 120 -Inadequate sleeping & 12.99 & 2.82 & 7 & 0 \\
\hline 126 -Suicide gesture/attempt & 35.47 & 4.79 & 3 & 0 \\
\hline 137-Lack of sexual arousal & 22.00 & 5.00 & 1 & 0 \\
\hline 175 -Suspiciousness & 17.60 & 4.00 & 1 & $\mathbf{0}$ \\
\hline 195-Low frustration tolerance & 0 & 0 & 1 & 0 \\
\hline 218-Excessive debt & -13.42 & -2.24 & 1 & 0 \\
\hline 225 -Social isolation & 2.89 & .60 & 5 & 0 \\
\hline 233 -Does not take prescribed medication & 16.80 & 3.00 & 1 & 0 \\
\hline
\end{tabular}

Figure 5. Report to a unit on problem treatment.

The second management information program provides administrators with information on treatment decision making and effectiveness. This report is shown in Figure 4. It begins with a summary, organized by treatment unit, of the disability difference (outcome) scores for each patient, averages for each therapist, and averages for the units. The report then shows the outcome of treatment by problem (Figure 5). For each problem the report lists the number of times it was treated or deferred and the average disability difference for that problem. This report provides managers with information as to the work-load distribution within the system. It also identifies which problems are (or are not) being treated by each treatment unit and their relative treatment success.

\section{DISCUSSION}

The problem-oriented system illustrates our assertion that on-line technology is a fundamentally different medium from the paper-and-pencil medium. The instru- ment described in this paper consists of a relatively simple amalgamation of a list of problems, a set of weights, and a distance function. However, when coupled with an on-line computer system, it not only provides research data, but also summarizes an assessment battery, sets treatment priorities, records treatment decisions, provides feedback on the functioning of a mental health facility, and provides information necessary for objective resource allocation. An instrument with this flexibility would have been impossible to implement in the paper-and-pencil medium.

\section{REFERENCE NOTES}

1. Cautela, J. R. \& Upper, D. A behavioral coding system. Presidential Address presented at the annual meeting of the Association for the Advancement of Behavior Therapy, Miami, December 1973.

2. Wilson, N. C., Ellis, R. H., Booth, R. E., \& Mumpower, J. Treatment effectiveness, program evaluation, and ATGON. Unpublished manuscript, Fort Logan Mental Health Center, Denver. 1973. 


\section{REFERENCES}

BLock, J. The $Q$-sort method in personality assessment and psychiatric research. Springfield, Ill: Charles C Thomas, 1961.

GaRwick, G., \& Lampman, S. Typical problems bringing patients to a community mental health center. Community Mental Health Joumal, 1972, 8, 271-280.

Giannetti, R. A., Klingler, D. E., Johnson, J. H., \& WILliams, T. A. The potential for dynamic assessment systems using on-line computer technology. Behavior Research Methods \& Instrumentation, 1976, 8, 101-103.

Granturco, D. T. \& Ramm, D. Computer aided patient evaluation: A goal oriented approach. In J. L. Crawford, D. W. Morgan, \& D. T. Gianturco (Eds.), Progress in mental health information systems: Computer applications. Cambridge, Mass: Ballinger, 1974.

Johinson, J. H., Giannetti, R. A., \& Williams, T. A. Real- time psychological assessment and evaluation of psychiatric patients. Behavior Research Methods \& Instrumentation, 1975, 7, 199-200.

Johnson, J. H. \& Williams, T. A. The use of on-line computer technology in a mental health admitting system. American Psychologist, 1975, 30, 388-390.

Kiresuk, T. J. \& Sherman, R. E. Goal attainment scaling: A general method for evaluating comprehensive community mental bealth programs. Community Mental Health Journal, 1968, 4, 443-453.

Luborsky, L. Clinicians' judgments of - mental health. Archives of General Psychiatry, 1962, 7, 407-417.

WEED, L. L. Medical records, medical education, and patient care: The problem-oriented record as a basic tool. Cleveland: Case Western Reserve University Press, 1969.

Williams, T. A., Johnson, J. H., \& Bliss, E. L. A computer-assisted psychiatric assessment unit. American Journal of Psychiatry, 1975, 132, 1074-1076. 